\title{
Analyzing the Harmonic Distortion in a Distribution System Caused by the Non-Linear Residential Loads
}

\author{
Haroon Farooq*, Chengke Zhou, Mohamed Emad Farrag \\ School of Engineering and Built Enviorment, Glasgow Caledonian University, Cowcaddens Road, Glasgow, G4 0BA, UK
}

\begin{abstract}
Harmonic distortion has garnered a lot of interest in the recent past due to the high advent of the non-linear electronic loads. Moreover, newer technologies including distributed generation and electric vehicles are anticipated to be part of the distribution systems at a mass scale in the near future. This makes it of utmost importance to evaluate the existing power distribution systems and analyze the possible constraints. This research study makes an effort to evaluate the harmonic distortion in the distribution systems caused by the various non-linear residential loads. The experimentally developed harmonic spectrums, of several home appliances, are deployed for the simulation of a typical UK distribution system using Electrical Transient Analyzer Program (ETAP). The results show high level of harmonic distortion, at the Point of Common Coupling (PCC), in the distribution system which becomes even more aggravated when a higher loading level, of the distribution transformer, is considered.
\end{abstract}

Keywords: Harmonic distortion, distribution systems, non-linear loads

\section{Introduction}

Power quality has enjoyed an increased interest in the recent years because the non-linear residential loads which draw non-sinusoidal current are increasing day by day [1]. This is due to the fact that most of the home appliances including Television (TV), HiFi systems, Compact Fluorescent Lamps (CFL), Personal Computers (PC) and different devices chargers use the rectification phenomena producing harmonic distortion [2]. Harmonic distortion can be described as the production of the unwanted frequency components as the integer multiple of the fundamental frequency component [3]. A term generally deployed to compute the harmonic pollution is Total Harmonic Distortion (THD) which can be defined as: "The ratio of the harmonic content to the fundamental quantity, expressed as a percentage" [4].

$$
\text { (\%)THD }=\frac{\sqrt{\sum_{h=2}^{\infty} M_{h}^{2}}}{M_{1}} \times 100
$$

where $M_{1}$ and $M_{h}$ represent the magnitude of the fundamental and the $h$ th harmonic component, respectively, of the current or the voltage waveform. According to the IEEE standard [5], Total Harmonic Distortion in Voltage $\left(\mathrm{THD}_{v}\right)$ and Individual Harmonic Distortion in Voltage $\left(\mathrm{IHD}_{v}\right)$ for the system voltage level up to $69 \mathrm{kV}$ should not go beyond $5 \%$ and $3 \%$ respectively whereas the limits for the Individual Harmonic Distortion in Current $\left(\mathrm{IHD}_{i}\right)$ are given in Table 1.

The higher level of harmonic distortion in a distribution system reduces the efficiency of the system because of the increased line and transformer losses [6].

\footnotetext{
* Manuscript received June 15, 2012; revised August 7, 2012.

Corresponding author. Tel.: +44-141-331-3743; E-mail address: haroon.farooq@gcu.ac.uk
} 
Table $1 . \mathrm{IHD}_{i}$ limits

\begin{tabular}{cccccc}
\hline Harmonic Order & $h<11$ & $11 \leq h<17$ & $17 \leq h<23$ & $23 \leq h<35$ & $h \geq 35$ \\
\hline$\% \mathrm{IHD}_{\mathrm{i}}$ & 15.0 & 7.0 & 6.0 & 2.5 & 1.4 \\
\hline
\end{tabular}

Efforts have been carried out at different scales to analyze the harmonic pollution, produced by the residential loads, and the potential impacts on the distribution systems. Different research works were carried out to investigate the harmonic distortion produced by the PCs, CFLs, printers, gaming machines, washing machines and microwave ovens [7-12]. However, all these works considered either only one or only a few home appliances to access the impacts on the distribution systems, which makes it necessary to evaluate the combined effect of all these appliances and extend it further by including more household appliances. Therefore, it is necessary to develop a harmonic spectrum library of commonly used home appliances and then deploy it to evaluate the collective impact of all these appliances on a distribution system. This research work makes an effort to address this issue by combining the experimental and simulation results.

\section{Experimental Setup and Results}

An experimental setup, as shown in Fig. 1, was designed and implemented in the Smart Grid laboratory at Glasgow Caledonian University, UK, to analyze the harmonic spectrum (amplitude and phase spectrum) of the current waveform drawn by the various home appliances.

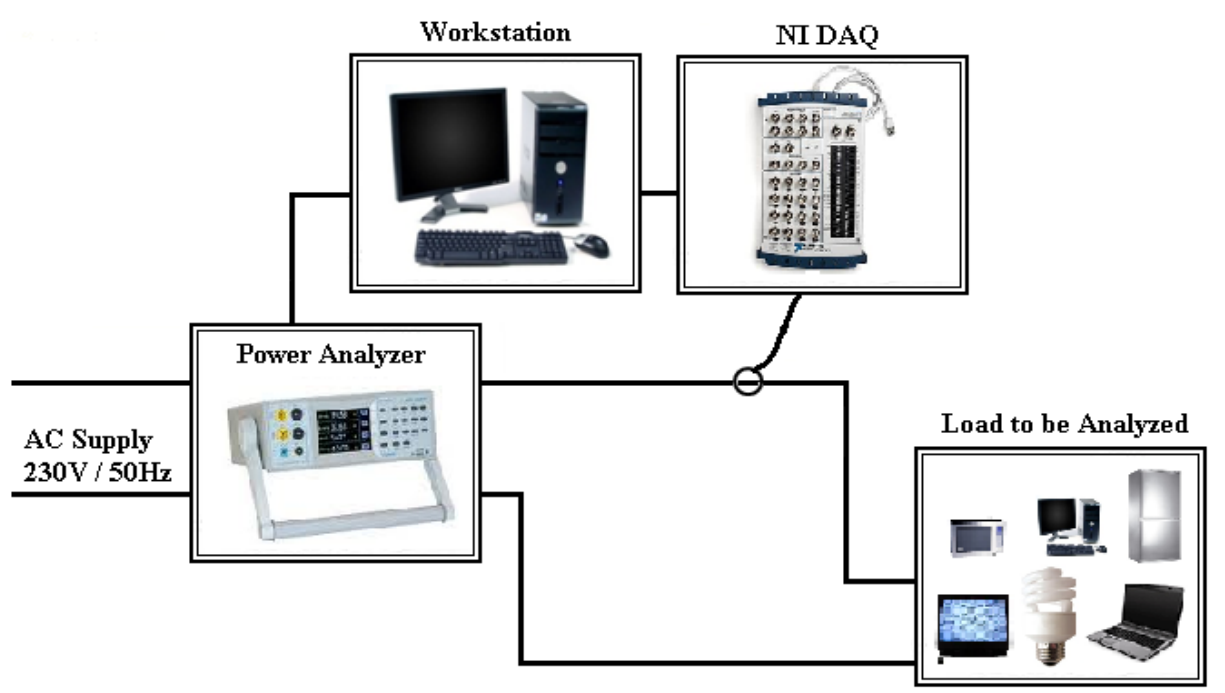

Fig. 1. Experimental setup

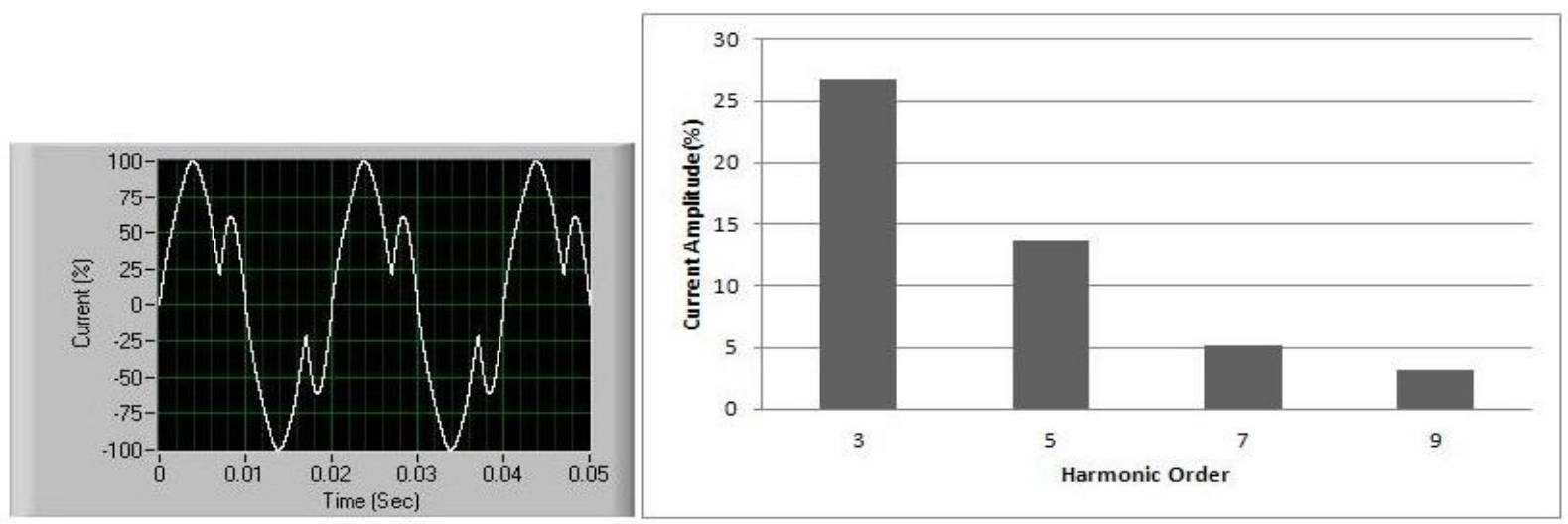

Fig. 2. Current waveform drawn by a microwave oven and its amplitude spectrum 
The current waveform drawn by a microwave oven along with its amplitude spectrum is shown in Fig. 2. The total harmonic distortion in the current waveform $\left(\mathrm{THD}_{i}\right)$ for the microwave oven was found to be $30.56 \%$, according to the IEEE standards, with a true power factor equal to 0.90 . True power factor $\left(\mathrm{PF}_{\text {true }}\right)$ is defined as the ratio of the total actual power $(P)$ to the total apparent power $(\mathrm{S})$, whereas, displacement power factor $\left(\mathrm{PF}_{\text {disp }}\right)$ is defined as the cosine of the angle between the respective fundamental components of the voltage and the current [13].

Similarly, the current waveforms drawn by CFL, freezer, fridge, refrigerator, TV, digital receiver box, DVD player, gaming console, PC, laptop, printer, and washing machine were also analyzed.

\section{Distribution system under study}

A typical UK distribution system, presented in [14], as shown in Fig. 3, in which a $500 \mathrm{kVA}$ transformer is supplying power to 100 homes, was considered for this study.

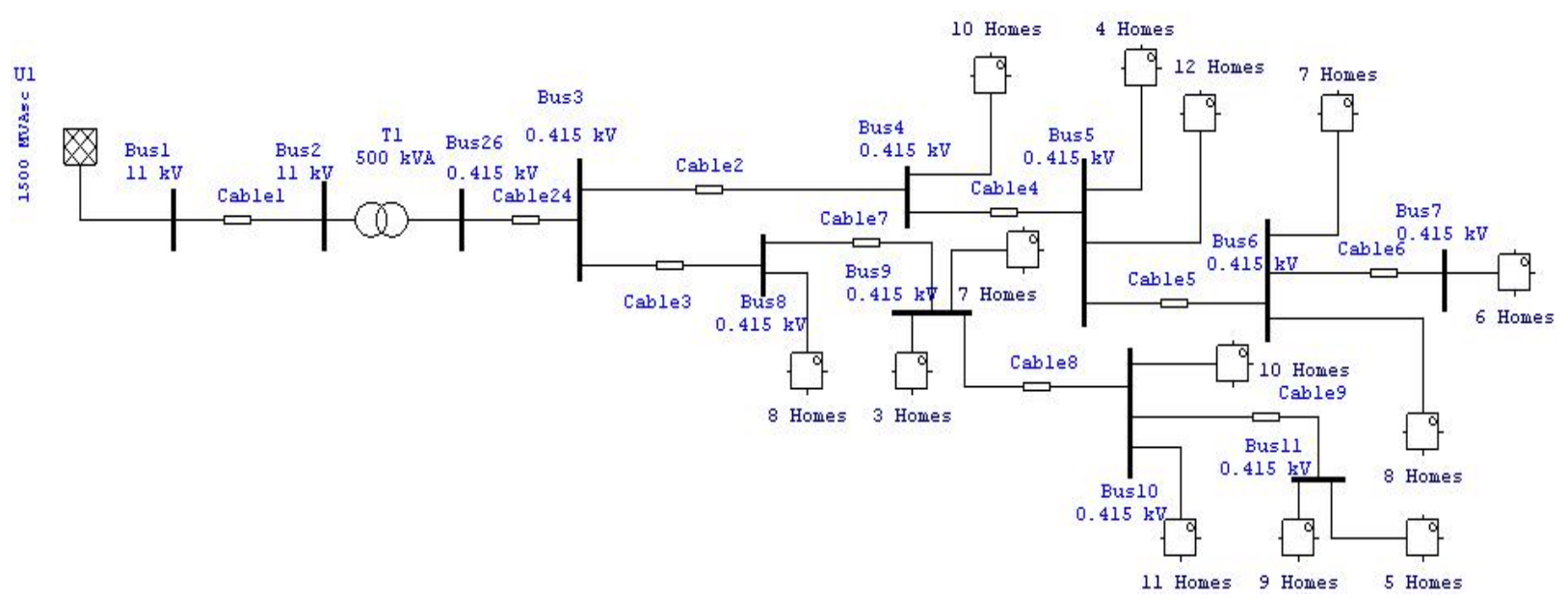

Fig. 3. One line diagram of the system under study

\section{Harmonic analysis}

Simulations were carried out, to obtain the voltage and current waveforms at Bus Bar 3 which is the Point of Common Coupling (PCC), a point where another consumer can be supplied [15], for all the homes, considering different loading levels of the distribution transformer. Reference [16] found that the average load on the distribution transformers does not exceed $20 \%$ loading. However, these are designed to give the maximum efficiency at approximately $75 \%$ loading [17]. Therefore, simulations were carried out at $20 \%$ and $75 \%$ loading of the distribution transformer to have a comparison. All the appliances mentioned in Section 2 were modelled as non-linear loads while the rest of the load was modelled as a linear load with a typical power factor of 0.85 [18]. The loading details are summarized in the Table 2.

The non-linear appliances mentioned in the table above represent $54.53 \%$ of the total loading which is in agreement with the UK National Statistics for the domestic loads [19].

Table 2. Loading details

\begin{tabular}{|c|c|c|c|c|c|c|c|c|}
\hline Loading & Appliance & CFL & Freezer & Fridge & Refrigerator & $\mathrm{TV}$ & $\mathrm{PC}$ & Printer \\
\hline $20 \%$ & \multirow{2}{*}{ Load (kW) } & 2.15 & 3.25 & 6.71 & 1.65 & 7.03 & 4.33 & 0.12 \\
\hline $75 \%$ & & 8.07 & 12.19 & 25.18 & 6.18 & 26.37 & 16.22 & 0.47 \\
\hline Loading & Appliance & \multicolumn{2}{|c|}{ DVD Player } & Laptop & \multicolumn{2}{|c|}{ Washing Machine } & \multicolumn{2}{|c|}{ Gaming Console } \\
\hline $20 \%$ & \multirow{2}{*}{ Load (kW) } & \multicolumn{2}{|l|}{2.10} & 0.77 & \multicolumn{2}{|l|}{3.63} & \multicolumn{2}{|l|}{0.64} \\
\hline $75 \%$ & & \multicolumn{2}{|l|}{7.87} & 2.90 & \multicolumn{2}{|l|}{13.61} & \multicolumn{2}{|l|}{2.41} \\
\hline Loading & Appliance & \multicolumn{3}{|c|}{ Microwave Oven } & \multicolumn{2}{|c|}{ Digital Receiver Box } & \multicolumn{2}{|c|}{ Linear Load } \\
\hline $20 \%$ & \multirow{2}{*}{ Load $(\mathrm{kW})$} & \multicolumn{2}{|c|}{2.03} & & \multicolumn{2}{|l|}{3.21} & \multicolumn{2}{|l|}{31.37} \\
\hline $75 \%$ & & \multicolumn{3}{|l|}{7.61} & \multicolumn{2}{|l|}{12.03} & \multicolumn{2}{|c|}{117.65} \\
\hline
\end{tabular}




\subsection{Current and voltage waveform at $20 \%$ loading}

Current waveform at bus bar 3 is shown in Fig. 4 and its amplitude spectrum is presented alongside it. The current waveform is highly distorted as compared to an ideal sine wave due to the high penetration of non-linear loads and has a $\mathrm{THD}_{\mathrm{i}}$ value of $42.20 \%$. The $3 \mathrm{rd}$, 5th, 7th, 11th and 13th harmonics, having an $\mathrm{IHD}_{i}$ of $24.76 \%, 17.82 \%, 20.20 \%, 11.80 \%$ and $8.17 \%$ respectively have values higher than the maximum standard values. When this highly distorted current flows through the system impedance it also causes the voltage waveform distortion. The voltage waveform at PCC and its amplitude spectrum are illustrated in Fig. 5.

The $\mathrm{THD}_{v}$ being equal to $3.70 \%$ is within the acceptable standard limit. Moreover, none of the individual harmonics crosses the standard threshold.

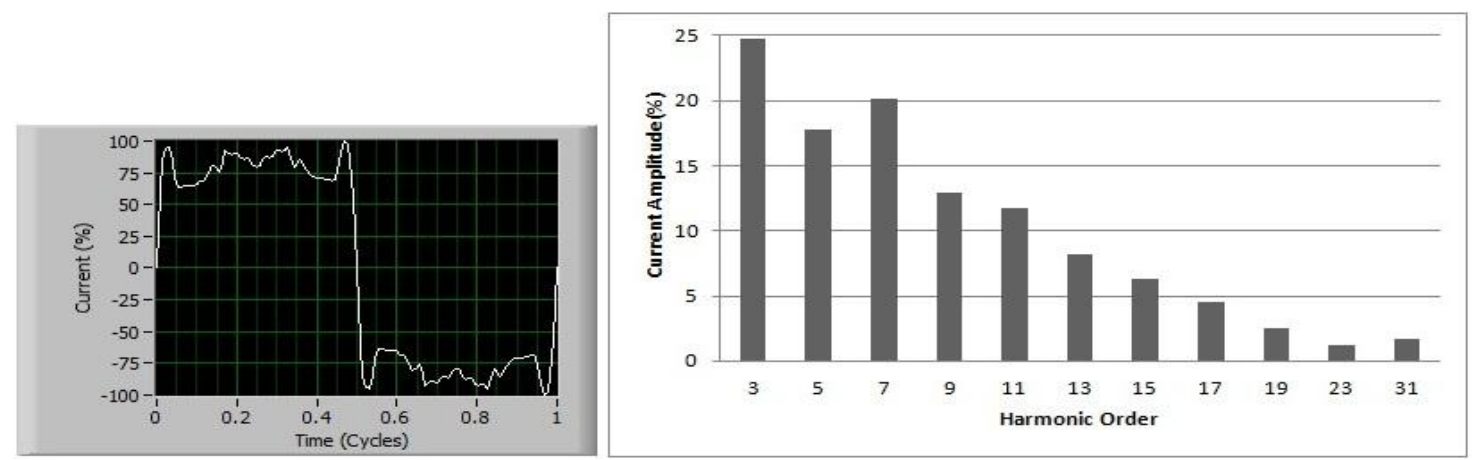

Fig. 4. Current waveform at PCC and its amplitude spectrum (20\% loading)
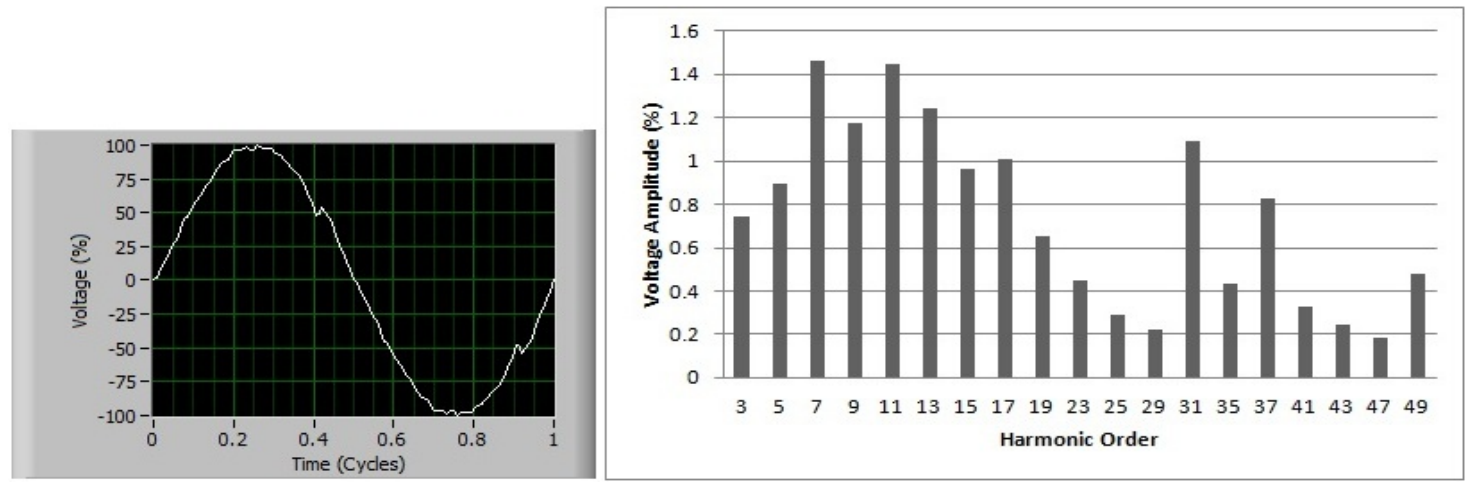

Fig. 5. Voltage waveform at PCC and its amplitude spectrum (20\% loading)

\subsection{Current and voltage waveform at $75 \%$ loading}

Current waveform at the PCC is shown in Fig. 6 and its amplitude spectrum is presented alongside it. The current waveform is highly distorted with a $\mathrm{THD}_{i}$ value of $42.74 \%$. The $3 \mathrm{rd}$, 5th, 7th, 11 th and 13th harmonics were found to be violating the standard limits.
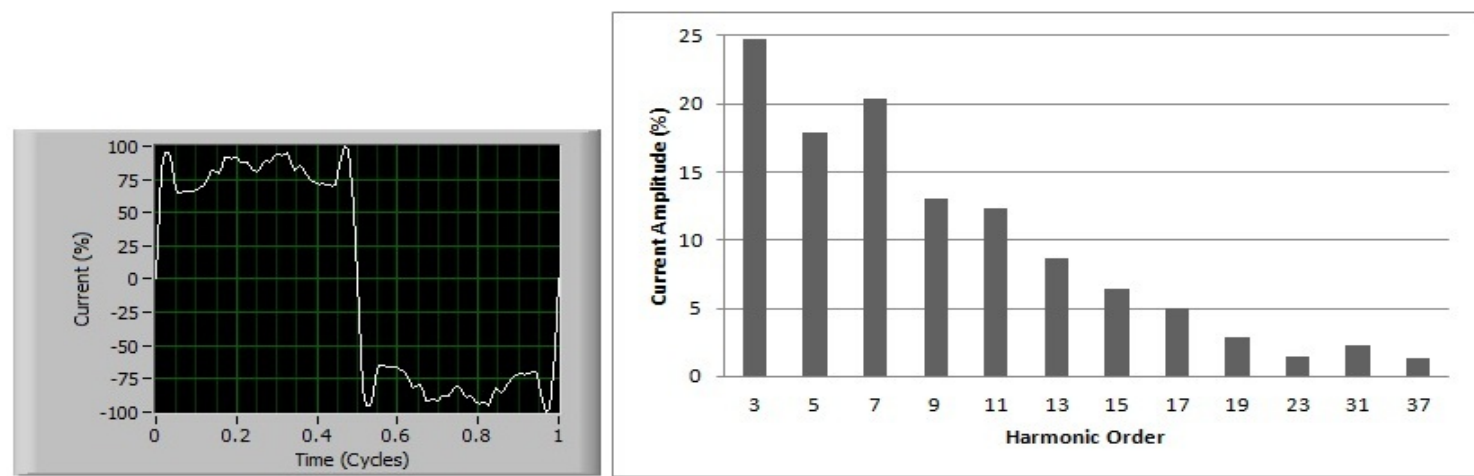

Fig. 6. Current waveform at PCC and its amplitude spectrum (75\% loading) 
The voltage waveform at PCC and its amplitude spectrum are presented in Fig. 7. $\mathrm{THD}_{\mathrm{v}}$ has an alarmingly high value equal to $12.51 \%$ which is very high as compared to the $\operatorname{THD}_{v}(3.70 \%)$ at $20 \%$ loading. In addition to the $\mathrm{THD}_{v}, 5$ th, 7 th, 9th, 11th, 13th, 15th, 17th and 31st harmonics also fail to satisfy the standard values set for $\operatorname{THD}_{v}(5 \%)$ and $\operatorname{IHD}_{v}(3 \%)$ respectively.

Even though the distribution transformers are designed to have the maximum efficiency at $75 \%$ loading, however, the increased harmonic pollution will reduce the overall efficiency of the system due to the increased system losses as mentioned in Section 1.

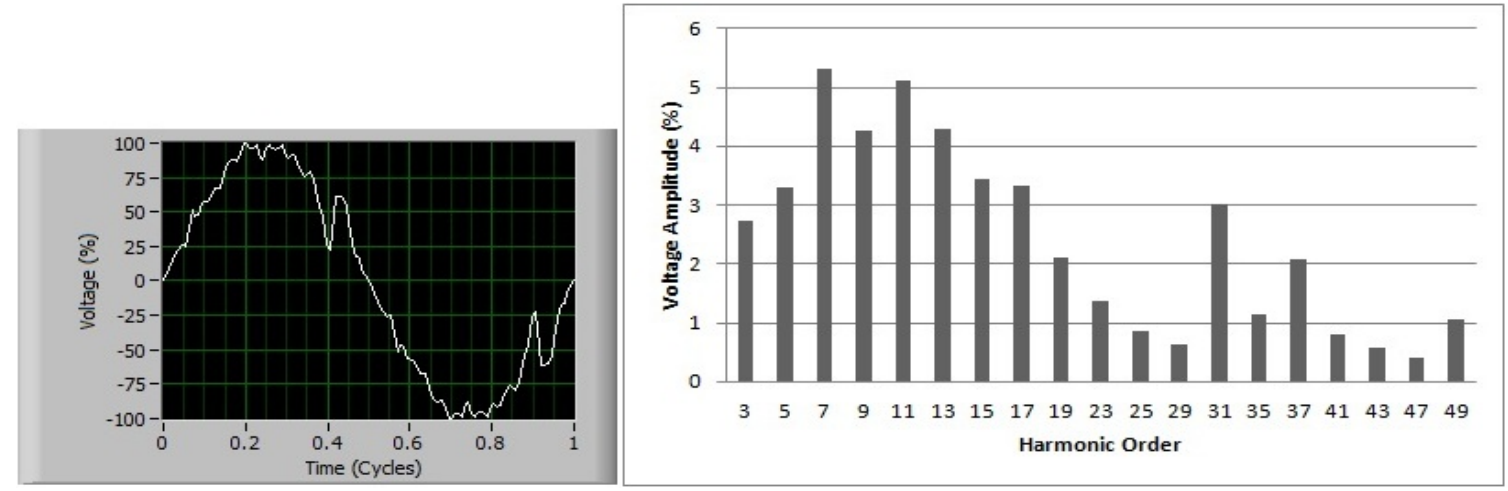

Fig. 7. Voltage waveform at PCC and its amplitude spectrum (75\% loading)

\section{Conclusions}

The experimental results combined with the simulation results showed that most of the home appliances draw highly distorted current waveform which produces a high level of harmonic distortion when connected to a distribution system. The situation becomes even more critical when the high level loading of the distribution transformers is considered which forces the $\mathrm{THD}_{\mathrm{v}}$, at $\mathrm{PCC}$, to go beyond the standard limit along with several other individual harmonic components. Therefore, operating the distribution transformers near the maximum efficiency may not be as beneficial as anticipated due to the increased losses incurred by the elevated harmonic pollution. Considering a co-relation between the harmonic distortion and the loading level, it is necessary to investigate the harmonic distortion variation throughout the day as the load varies. This will help the utility engineers to design more robust distribution systems against the harmonic distortion. Moreover, the results will be useful in raising the awareness among the masses, and all the stake holders in the power industry, regarding the harmonic pollution in the distribution systems and its consequences.

\section{References}

[1] Au MT, Navamany JS, Yeoh EC. Impact of medium power inverter-based residential harmonic loads and PFCs on low voltage lines. In: Proc. of IEEE International Conference on Power and Energy. 2010:695-699.

[2] Hardie S, Watson N. The effect of new residential appliances on power quality. In: Proc. of Australasian Universities Power Engineering Conference, 2010:1-6.

[3] L. Cividino. Power factor, harmonic distortion; causes, effects and consideration. In: Proc. of International Telecommunications Energy Conference, 1992:506-513.

[4] De Capua C, Romeo E. A smart THD meter performing an original uncertainty evaluation procedure. IEEE Trans. on Instrumentation and Measurement, 2007; 56(4):1257 - 1264.

[5] Recommended practices and requirements for harmonic control in electric power systems, IEEE SM 519-1992 (1992).

[6] Farooq H, Zhou C, Allan M, Farrag ME, Khan RA, Junaid M. Investigating the power quality of an electrical distribution system stressed by non-linear domestic appliances. Presented at: 2011 International Conference on Renewable Energies and Power Quality.

[7] Sharma VK, Moinuddin Doja MN , Ibraheem Khan MA. Power quality assessment and harmonic comparison of typical nonlinear electronic loads. In: Proc. of IEEE Conference on Industrial Technology 2000:729-734. 
[8] Testa A, Langella R. Harmonic pollution in Italian distribution networks in coincidence with important sport events. In: Proc. of IEEE Power Engineering Society General Meeting, 2007:1-7.

[9] Dwyer R, Khan AK, Mcgranaghan M, Tang L, Mccluskey RK, Sung R, Houy T. Evaluation of harmonic impacts from compact fluorescent lights on distribution systems. IEEE Trans. on Power Systems, 1995; 10(4):1772-1779.

[10] Haiduck R, Baghzouz Y. Characteristics of harmonic currents generated by a cluster of gaming machines. In: Proc. of International Conference on Harmonics and Quality of Power, 2002:398 - 402.

[11] Dianov A, Lee ST. Novel IPMSM drive for compact washing machine. In: Proc. of International Telecommunications Energy Conference 2009:1-7

[12] Miyata E, Hishikawa S, Matsumoto K, Nakaoka M, Bessyo D, Yasoi K, Hirota I, Omori H. Quasi-resonant ZVS-PWM inverter-fed DC-DC converter for microwave oven and its input harmonic current evaluations. In: Proc. of Annual Conference of IEEE Industrial Electronics Society, 1999:773-778.

[13] Theodore Wildi. Electrical Machines, Drives, and Power Systems. Bergen: Prentice Hall; 2002.

[14] Farooq H, Qian K, Farrag ME, Allan M, Zhou C. Power quality analysis of distribution systems incorporating high penetration level of EV battery chargers. Present at: 2011 International Conference and Exhibition on Electricity Distribution.

[15] Hansen D. IEEE 519 misapplications - point of common coupling issues. In: Proc. of IEEE Power and Energy Society General Meeting - Conversion and Delivery of Electrical Energy in the 21st Century, 2008:1-3.

[16] Giraldo O. New vision on the real average load of transformers in the Latin America's distribution networks, In: Proc. of IEEE/PES Transmission and Distribution Conference and Exposition: Latin America, 2008:1-5.

[17] Kothari DP, Nagrath IJ. Electric Machines. 3rd ed. Delhi: Tata McGraw-Hill; 2006.

[18] Guo LX, Cheng Y, Zhang LZ, Huang HT, Research on power-factor regulating tariff standard, In: Proc. of International Conference on Electricity Distribution, 2008:1-5.

[19] Department of Energy and Climate Change. Domestic data tables. National Statistics, 2011. 